\title{
BUILDING INFORMATION MODELLING DEMYSTIFIED: DOES IT MAKE BUSINESS SENSE TO ADOPT BIM?
}

\author{
Guillermo Aranda-Mena ${ }^{\dagger}$, John Crawford ${ }^{\dagger}$, Agustin Chevez ${ }^{\dagger}$, Thomas Froese ${ }^{\S}$
}

† School of Property, Construction and Project Management, RMIT University, Australia

e-mail: \{Guillermo.Aranda-Mena, John.Crawford, Agustin.Chevez \} @rmit.edu.au

${ }^{\S}$ Department of Civil Engineering, University of British Columbia, Vancouver, Canada, e-mail: Thomas.Froese@ubc.caＴelephone (604) 822-2027

\begin{abstract}
Building Information Modeling (BIM) offers a revolutionising way to design, document and procure buildings. BIM promises to become a new international benchmark for building design and documentation across industry on the basis of improved efficiencies and collaboration capabilities. However, BIM requires rethinking current practices and process thus it calls for a paradigm shift in the way we procure, design and operate buildings. There seems no question that BIM methodologies are to become the norm in the long term but more factual evidence is required today to provide guidance to industry. This paper investigates current business drivers for BIM adoption by architecture and building engineering consultants.

BIM needs to compete against well-ingrained methods to deliver projects in a fragmented and rather traditional industry. This paper investigates 47 value propositions for the adoption of BIM under a multiple case study investigation carried out in Australia and Hong Kong (Aranda-Mena et. al 2008). The selected case study projects included a range of public (1) and private (4) sector building developments of small and large scale. Findings were coded, interpreted and synthesised in order to identify the challenges and business drivers, and the paper focuses mainly on challenges and benefits for architectural and engineering consultants, contractors and steel fabricators. As a condition for the selection criteria all case studies had to be collaborating by sharing BIM data between two or more consultants / stakeholders. As practices cannot afford to ignore BIM this paper aims to identify those immediate business drivers as to provoke debate amongst the professional and academic community.
\end{abstract}

\section{INTRODUCTION}

Current problems with design and construction quality and efficiencies are clear calls for action to improve an industry that remains behind any other in its attempt to become more competitive and provide a better service to clients and society as a whole - to reduce disputes and to share risks and move the industry forward into the $21^{\text {st }}$ century. A well known finding by the NIST (2004) states that over US\$15.8 billion is lost every year due to the lack of interoperability in the capital facilities in the US alone, while a more recent response is the mandate of the General Services Administration (GSA) to require new building documentation be prepared in a BIM technological software.

The aim of the paper is to report on findings on business drivers for Building Information Modelling (BIM) and to provoke wider debate on the speed of adoption. The paper draws upon five case studies originally set to demystify myths surrounding 'Business Drivers for BIM' (Aranda-Mena et.al 2008). Froese et al. (2008) provides a detailed description of the structured study, data analysis and alignment with the Val IT business framework (ITGI 2006). On the other hand Crawford et. al (2008) presents a concise summary of Business Drivers for BIM. Both papers were intended to disseminate findings and value propositions to property owners, operators, contractors and consultants. This paper focuses on specific findings to consulting practices in architecture and engineering.

Taking the premise that practices cannot afford NOT to invest in BIM technologies this paper was set to investigate business drivers for BIM. The paper is based on a larger investigation sponsored by the CRC for 
Construction Innovation representing a number of private and public sector architectural and construction organisations (www.crcci.info). The investigation was carried out during 2007 by researchers from RMIT University, Melbourne and QUT University, Brisbane, whereby the overall investigation was set as a project to identify factual evidence on business drivers for BIM as a response to the plethora of myths and misconceptions currently surrounding BIM.

\subsection{WHAT IS BIM?}

One might think that BIM needs no introduction but it should come as no surprise that currently BIM is an ambiguous term that means different things to different professionals. This was also confirmed by empirical results found by this study indicating that BIM is not only defined in various ways according to particular professions but that there is also confusion at three different levels; for some, BIM is a software application (1); for others it is a process (2) for designing and documenting building information; for others it is a whole new approach to practise and advancing the profession which requires the implementation of new policies (3), contracts and relationships amongst project stakeholders.

There are a number of views in industry and academia as to what constitutes BIM. An abundance of definitions related to BIM have emerged with terms including object-oriented modelling, project modelling, virtual design and construction, virtual prototyping, integrated project databases and the more recent term Building Information Modelling.

Amor (2001) identified a number of definitions including:

- Gann et al. (1996) 'a single project database as an electronic data model to which all participants refer throughout the process of design, construction, operation and maintenance'.

- Björk and Penttilä (1989) ' project models are conceptual structures specifying what kind of information is used to describe buildings and how such information is structured’.

- Fisher et al. (1997) 'project modelling is object modelling applied to a project and including more information than just geometry’

Synonyms of BIM include terms such as $n D$ modelling employed by Salford University:

- "An nD model is an extension of the building information model, which incorporates multi-aspects of design information required at each stage of the lifecycle of a building facility"

Construct IT, University of Salford, UK, 2003

The term Building Information Modelling (BIM) as such was originally popularised by Jerry Laiserin, referring to the ability to use, reuse and exchange information, of which electronic documents are just a single component:

- $\mathrm{BIM}$ is much more than 3D rendering or transferring electronic versions of paper documents. By implementing BIM "risk is reduced, design intent is maintained, quality control is streamlined, communication is clearer, and higher analytic tools are more accessible"

AIA 2005 website.

More recent material offers several BIM definitions. However, they all seem to agree that BIM is a digital representation of the building. Following are two alternatives that encompass views of two of the leading organisations in the field.

- "A BIM is a digital representation of physical and functional characteristics of a facility. As such it serves as a shared knowledge resource for information about a facility forming a reliable basis for decisions during its life-cycle from inception onward."

BuildingSMART website. 
Complementing the architectural domain the American General Contractors defines BIM as:

- "Building Information Modeling is the development and use of a computer software model to simulate the construction and operation of a facility. The resulting model, a Building Information Model, is a data-rich, object-oriented, intelligent and parametric digital representation of the facility, from which views and data appropriate to various users' needs can be extracted and analyzed to generate information that can be used to make decisions and improve the process of delivering the facility. The process of using BIM models to improve the planning, design and construction process is increasingly being referred to as Virtual Design and Construction (VDC)."

The Contractors’ Guide to BIM (AGC 2006)

Succar et. al (2007) defined BIM as "a set of interacting policies, processes and technologies producing a methodology to manage the essential building design and project data in digital format throughout the building's life-cycle”. They argued that BIM is an emerging technological and procedural shift affecting all stakeholders within the Architecture, Engineering and Construction industry with the resulting problems of semantics and a variety of connotations to those engaged with it.

Empirical results of this particular study align with those BIM problems of meaning and interpretation. It is expected that as BIM becomes a mainstream methodology the formal definition will be less of an issue as professionals start to understand the inherent attributes and characteristics. Discussions with professional bodies have started as to usage of wording and terminology linking geography and context.

\section{CASE STUDIES}

This section describes five in-depth case studies where small, medium and large architectural and engineering practices were involved. The study identified current and future issues related to business drivers and inhibitors towards the uptake of BIM. All selected case studies had some level of BIM data exchange with at least one other discipline - including architectural, design documentation and structural engineering. The research design and case study protocol was informed by Yin's (1994) methodology.

This paper takes the premise that BIM is not an option but the emerging order for architectural, building engineering consultants. Practices cannot afford not to adopt BIM and thus it is paramount to identify the right timing when to start the transitional shift for practices that want to adopt it. This paper evaluates such change management process against a business model (refer to Aranda-Mena et.al 2008). 


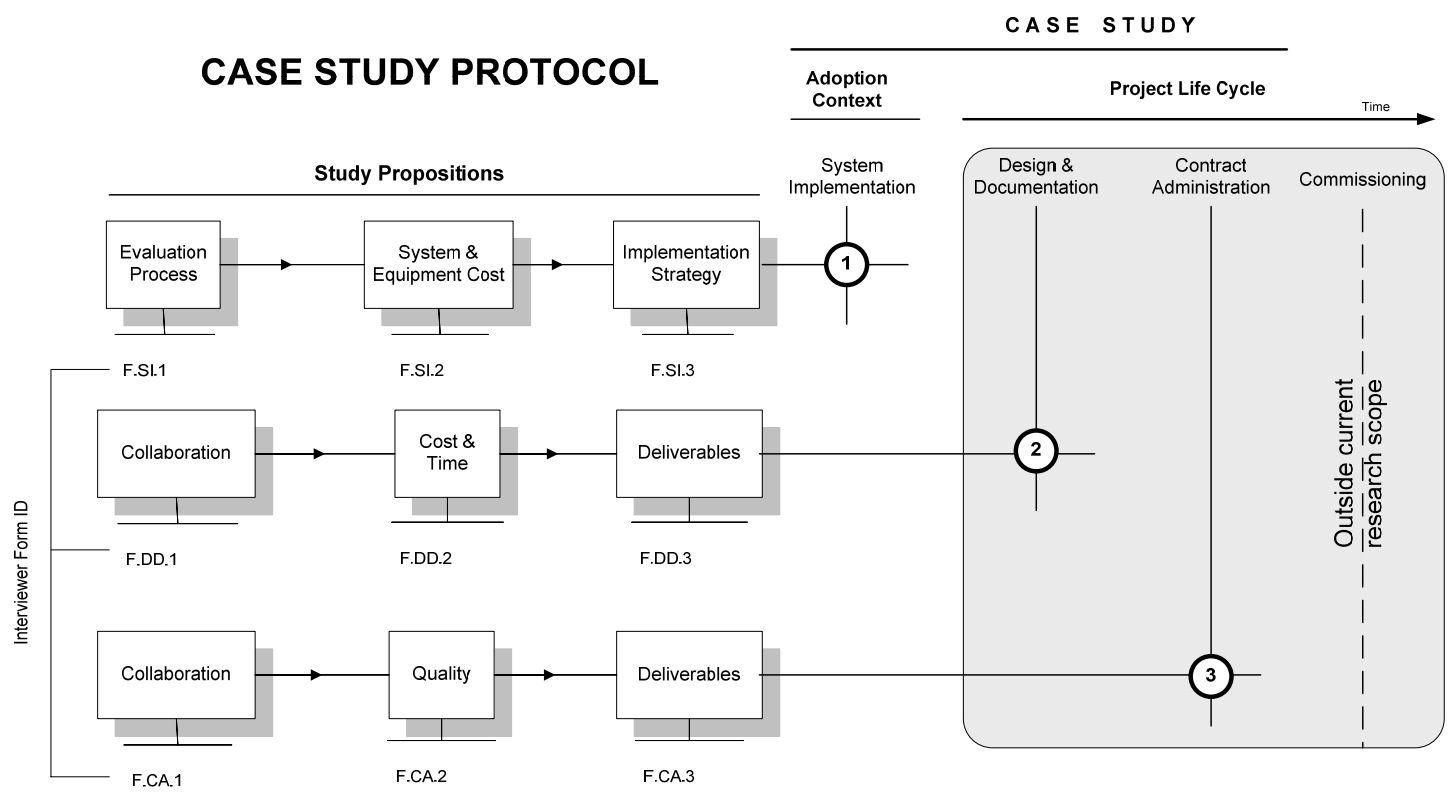

Figure 1. Case Studies: propositions within context and project life cycle

The research protocol (Figure 1) ensures that an acceptable level of data collection rigour takes place across all five case studies. The research protocol summarises all aspects investigated in each case study including 'organisational level' (node 1): BIM system 'evaluation', 'equipment cost', and 'implementation' strategies. At 'project level' (nodes 2 and 3) areas of investigation included 'project life cycle' especially aspects of 'design', 'documentation' and 'contract administration'. Case studies also targeted respondents at three organisational levels including (1) junior designer/draftsman, (2) project designer/manager and (3) CEO/Executive. A total of three pilot interviews and 18 full investigation interviews where conducted (refer to Table 1).

Case studies were selected based on the following criteria:

a) BIM adopters: The first criteria for selecting a project as case study was that it must had been done using at least one of the BIM systems as previously identified in the literature review by at least one party, in this case the architect. Case Studies where BIM collaboration between consultants occurred were preferred.

b) Project Life Cycle: The selected project needed to have at least commenced, or just about to start, construction. This would allow the study to evaluate the performance of BIM during this critical stage (e.g. reduction in RFI's, generation of “as-builts'). Refer to Figure 1.

c) Variety of BIM authoring software: Since the research does not aim to study, or promote, any particular BIM application, it was intended that case studies should use different systems. However, most of the suitable case studies were using Revit and ArchiCAD software. One case study used Digital Project (from Gehry Technologies based on CATIA) and another involved the partial use of Bentley's software.

d) Variety of company / project size: In order to allow readers to identify with a particular case study, or between two of them, an array of different size projects was preferred. 
Table 1. Case Studies Undertaken

\begin{tabular}{|c|c|c|c|c|c|}
\hline & $\begin{array}{l}\text { Cas } \\
\text { e } \\
\text { Stud } \\
\text { y_1 }\end{array}$ & $\begin{array}{l}\mathrm{CS}_{-} \\
2\end{array}$ & $\begin{array}{l}\mathrm{CS}_{-} \\
3\end{array}$ & $\begin{array}{l}\mathrm{CS}_{-} \\
4\end{array}$ & $\begin{array}{l}\text { CS } \\
5\end{array}$ \\
\hline $\begin{array}{l}\text { Majo } \\
\text { r } \\
\text { stake- } \\
\text { holde } \\
\text { rs }\end{array}$ & $\begin{array}{l}\text { archi } \\
\text { tects } \\
\text { str. } \\
\text { engi } \\
\text { neer } \\
\text { s } \\
\text { mec } \\
\text { h } \\
\text { engi } \\
\text { n'rs } \\
\text { quan } \\
\text { tity } \\
\text { surv } \\
\text { eyor } \\
\text { deve } \\
\text { loper } \\
\text { meta } \\
\text { l } \\
\text { fabri } \\
\text { c'r } \\
\text { buil } \\
\text { der }\end{array}$ & $\begin{array}{l}\text { archi } \\
\text { tects } \\
\text { str. } \\
\text { engi } \\
\text { neers } \\
\text { mec } \\
\text { h } \\
\text { engi } \\
\text { n'rs } \\
\text { deve } \\
\text { loper } \\
\text { build } \\
\text { er }\end{array}$ & $\begin{array}{l}\text { archi } \\
\text { tects } \\
\text { inter } \\
\text { ior } \\
\text { archi } \\
\text { tects } \\
\text { str. } \\
\text { engi } \\
\text { neer } \\
\text { s } \\
\text { deve } \\
\text { loper } \\
\text { buil } \\
\text { der }\end{array}$ & $\begin{array}{l}\text { archi } \\
\text { tects } \\
\text { str. } \\
\text { engi } \\
\text { neers } \\
\text { mec } \\
\text { h } \\
\text { engi } \\
\text { n'rs } \\
\text { IT } \\
\text { man } \\
\text { ag't } \\
\text { deve } \\
\text { loper } \\
\text { build } \\
\text { er }\end{array}$ & $\begin{array}{l}\text { archi } \\
\text { tects } \\
\text { str. } \\
\text { engi } \\
\text { neers } \\
\text { mec } \\
\text { h } \\
\text { engi } \\
\text { n'rs } \\
\text { deve } \\
\text { loper } \\
\text { (gov } \\
\text { ) } \\
\text { build } \\
\text { er }\end{array}$ \\
\hline $\begin{array}{l}\text { Est'd } \\
\text { cost }\end{array}$ & $\begin{array}{l}\$ 300 \\
M\end{array}$ & $\$ 4 M$ & $\begin{array}{l}\$ 280 \\
M\end{array}$ & $\begin{array}{l}\$ 300 \\
M\end{array}$ & $\begin{array}{l}\$ 10 \\
M\end{array}$ \\
\hline $\begin{array}{l}\text { Timef } \\
\text { rame }\end{array}$ & $\begin{array}{l}2 \\
\text { year } \\
\text { s }\end{array}$ & $\begin{array}{l}6 \\
\text { mont } \\
\text { hs }\end{array}$ & $\begin{array}{l}18 \\
\text { mon } \\
\text { ths }\end{array}$ & $\begin{array}{l}3 \\
\text { years }\end{array}$ & $\begin{array}{l}12 \\
\text { mont } \\
\text { hs }\end{array}$ \\
\hline $\begin{array}{l}\text { Locat } \\
\text { ion }\end{array}$ & $\begin{array}{l}\text { centr } \\
\text { al } \\
\text { city }\end{array}$ & $\begin{array}{l}\text { inner } \\
\text { urba } \\
\mathrm{n}\end{array}$ & $\begin{array}{l}\text { centr } \\
\text { al } \\
\text { city }\end{array}$ & $\begin{array}{l}\text { inner } \\
\text { urba } \\
\text { n }\end{array}$ & $\begin{array}{l}\text { rural } \\
\text { town }\end{array}$ \\
\hline $\begin{array}{l}\text { BIM } \\
\text { autho } \\
\text { ring } \\
\text { tool(s) }\end{array}$ & $\begin{array}{l}\text { Arch } \\
\text { icad }\end{array}$ & $\begin{array}{l}\text { Arch } \\
\text { icad }\end{array}$ & $\begin{array}{l}\text { Arch } \\
\text { icad } \\
\text { Revi } \\
\text { t } \\
\text { Bent } \\
\text { ley }\end{array}$ & $\begin{array}{l}\text { Digit } \\
\text { al } \\
\text { Proje } \\
\text { ct }\end{array}$ & $\begin{array}{l}\text { Arch } \\
\text { icad } \\
\text { Revi } \\
\mathrm{t}\end{array}$ \\
\hline $\begin{array}{l}\text { Interv } \\
\text { iews }\end{array}$ & 3 & 3 & 6 & 3 & 3 \\
\hline
\end{tabular}




\begin{tabular}{|c|c|c|c|c|c|}
\hline & $\begin{array}{l}\text { Cas } \\
\text { e } \\
\text { Stud } \\
\text { y_1 }\end{array}$ & $\begin{array}{l}\mathrm{CS}_{-} \\
2\end{array}$ & $\begin{array}{l}\mathrm{CS}_{-} \\
3\end{array}$ & $\begin{array}{l}\mathrm{CS}_{-} \\
4\end{array}$ & $\begin{array}{l}\mathrm{CS}_{-} \\
5\end{array}$ \\
\hline $\begin{array}{l}\text { Exten } \\
\text { t of } \\
\text { data } \\
\text { excha } \\
\text { nge }\end{array}$ & $\begin{array}{l}\text { archi } \\
\text { tects } \\
\text { with } \\
\text { str. } \\
\text { Engi } \\
\text { neer } \\
\text { s } \\
\text { (elec } \\
\text { troni } \\
\text { c } \\
\text { data } \\
\text { flow } \\
\text { was } \\
\text { one- } \\
\text { way } \\
\text { only) }\end{array}$ & $\begin{array}{l}\text { archi } \\
\text { tects, } \\
\text { str. } \\
\text { engi } \\
\text { neers }\end{array}$ & $\begin{array}{l}\text { archi } \\
\text { tects } \\
\text { with } \\
\text { str. } \\
\text { engi } \\
\text { neer } \\
\text { s }\end{array}$ & $\begin{array}{l}\text { archi } \\
\text { tects, } \\
\text { str. } \\
\text { engi } \\
\text { neers } \\
\text { mec } \\
\text { h } \\
\text { engi } \\
\text { n'rs } \\
\text { IT } \\
\text { grou } \\
\text { p, } \\
\text { deve } \\
\text { loper } \\
\text { build } \\
\text { er }\end{array}$ & $\begin{array}{l}\text { archi } \\
\text { tects, } \\
\text { str. } \\
\text { engi } \\
\text { neers } \\
\text { mec } \\
\text { h } \\
\text { engi } \\
\text { n'rs } \\
\text { deve } \\
\text { loper } \\
\text { (gov } \\
\text { ) } \\
\text { build } \\
\text { er }\end{array}$ \\
\hline
\end{tabular}

The above Table 1 outlines five case studies and a brief description of size, cost and other characteristics such as BIM authoring tools and data exchanges. Note that there are a number of BIM related tools and code checkers such as NavisWorks or Solibri clash checkers. BIM authoring tools were the main focus of investigation rather than other types of BIM "behavioural analysis" software. 
Nine cluster categories where taken to code each of the interviews. The categories where originally highlighted by reference to the Val IT approach (ITGI 2006) and used in the overall investigation to align responses to a business model.

The Fact registry is a tabulation of all of the relevant facts that make up the business case analysis, and the ValIT Business case format decomposes the wide range of issues along several key dimensions. While these dimensions could be considered in any order, we have organised them into the following hierarchy to provide a specific sequence to the analysis. Not all items at all levels are required, but should be included in the fact registry as appropriate.

\section{- Level 1: Analysis Components}

At the top level, the information is organised according to the overall flow of the analysis, as follows:

* Initiatives: The business, process, people, technology, and organisational actions/projects undertaken to achieve the outcomes. Also, the contributions of each initiative to individual outcomes (where appropriate). Specific action items associated with the BIM implementation.

* $\quad$ Alignment Issues: The degree to which the program aligns with existing systems and practices, regulations, policies, and business strategies. Issues relating to the alignment of the BIM implementation program with existing systems and procedures

* Efficiency: Improvements to the efficiency of designing and managing building projects.

* Design Functionality: Issues that lead to better building designs.

* Collaboration: Improved support for collaboration among project participants.

* $\quad$ Other benefits: Other project and corporate benefits.

* $\quad$ Resources/expenses: Resource requirements for delivering the program, and Expenses incurred to provide the necessary resources, from reduced efficiencies, etc. The resource requirements for BIM, and the corresponding costs.

* $\quad$ Risks: Critical risks facing a program, including risk quantification and mitigation information Major risks associated with a BIM implementation.

* $\quad$ Assumptions/Constraints/Conditions: Issues describing assumed preconditions or constraints for BIM implementations

- Level 2: Capability Layers

The analytical components can be applied at each of three layers of business scope/focus:

* Technical Capability

The specific technological capabilities delivered by the program.

* $\quad$ Operational Capability The operational capabilities that are supported by the technological capabilities.

* $\quad$ Business Capability The overall business capabilities enabled by the operational capabilities.

- Level 3: Life cycle phases

The analysis information can be organised according to the life cycle phases required to build/create, implement/deploy, operate, and retire the program.

$\begin{array}{ll}* & \text { Build } \\ * & \text { Implement } \\ * & \text { Operate } \\ * & \text { Retire }\end{array}$




\section{- Level 4: Stakeholder}

Building projects involve large scale collaborations of stakeholders from many different organisations, and since collaboration issues are central to BIM technologies, the business case inevitably involves multiple stakeholders. The value propositions become considerably more complex since the parties that reap the benefits may differ from those that incur the expenses and risks. Thus, although not considered in the ValIT framework, it may often be relevant to define specific stakeholders' interests in each element of the program.

- Level 5: Outcome Range

Often, the expected results of the program cannot be forecast with very much precision, but can be described in terms of the best case and worst case extremes from a range of probable outcomes.

\section{* Best case}

* Worst case

Overall cumulative analysis of:

- Financial benefits

- Financial costs

- Non-financial benefits/alignment

- Risk Analysis

- Change impact

- The impact (positive and negative outcomes) of not doing the program. Including the opportunity costs - i.e., the net cost of foregoing the next best/status quo alternative.

\subsection{FINDINGS: CODING AND ANALYSIS}

"We had infused a very precise discipline into the whole design process where architects, engineering consultants, structural engineers, all had to design to the same precise vocabulary. I think it has been an incredible process of intuitive collaboration. It is all about project certainty. We know what we're designing, we know how much it's going to cost, we know how it's going to be built, and for us as a developer that is paramount to total success."

(Managing Director CS4)

This section describes assertions identified from respondents including issues that arose most often in discussions (i.e. had the greatest "weight of evidence") with the various respondents for each of the case studies, and are detailed below. Note: a full account of the project is beyond the scope of this paper, refer to Aranda-Mena et. al (2008) for detailed results analysis and interpretation.

\subsubsection{CASE STUDY CS1}

A multistorey office tower (with several basement levels) development located in a Central Business District of a major Australian city. The initial tower has recently been completed (2007) as one part (estimated construction value AU\$300 million) of a proposed two-stage project for the site.

Based on the interviews and discussions held with staff from various stakeholders, there was consistent agreement in Case Study CS1 with the propositions that BIM:

$>$ Improves information management/flow/sharing — associated with the category of Collaboration,

> Requires specialised software with certain characteristics — associated with Resources and Expenses

$>$ Improves evaluation of design scenarios — associated with Design Functionality

$>$ Improves efficiency — associated with Efficiency

$>$ Success is dependant upon selecting the correct software — associated with Initiatives 
$>$ Enhances confidence in the design outcomes — associated with Design Functionality

$>$ Improves co-ordination between consultants — associated with Collaboration

$>$ Requires a significant process re-structure (internal and external) — associated with Initiatives

> Adoption is hindered by legal frameworks — associated with Assumptions/Constraints

\subsubsection{CASE STUDY CS2}

A four-storey mixed hospitality/office development located some four kilometres from a major city centre in a 'suburban shopping strip' at a prominent intersection - surrounded by a mixture of commercial and retail businesses and nearby residential dwellings. Estimated construction value AU\$3.5 Million. Project at tendering stage and expected to start construction in 2008.

Based on the interviews and discussions held with a variety of staff from various stakeholders, there was consistent agreement in CS2 with the propositions that BIM:

$>$ Improves information management/flow/sharing — associated with the category of Collaboration

$>$ Improves efficiency — associated with Efficiency

$>$ Introduces new issues regarding ownership of information, IP, payment of information, etc. associated with Risks

$>$ Enhances confidence in the design outcomes — associated with Design Functionality

> Improves buildability — associated with Design Functionality

$>$ Improves co-ordination between some consultants — associated with Collaboration

$>$ Improves design — again associated with Design Functionality

$>$ Helps to align project stakeholders expectations — again associated with Collaboration

\subsubsection{CASE STUDY CS3}

A multistorey office tower development located at a waterside redevelopment close to the Central Business District of another major Australian city. A horizontal development rather than a high rise building, the scheme is designed blatantly to maximise floor space (33,000 sq $\mathrm{m}$ ).

Based on the interviews and discussions held with a variety of staff from various stakeholders, there was consistent agreement in CS3 with the propositions that BIM:

$>$ Requires leadership within the company — associated with the category of Assumptions / Constraints

$>$ Provides a foundation for FM processes — associated with Alignment

$>$ Requires appropriate training — associated with Initiatives

$>$ Improves design — associated with Design Functionality

$>$ Trained people are scarce — associated with Risks

$>$ Introduces new issues regarding ownership of information, IP, payment of information, etc. — associated with Risks

There was also consistent disagreement with the proposition that BIM requires a high economic investment — associated with Resources / Expenses 


\subsubsection{CASE STUDY CS4}

A commercial office building located on Hong Kong Island comprising of two basement levels and seventy storeys. Valued at HK\$2 Billion (AU\$300 Million) the project is due for completion in 2008.

Based on the interviews and discussions held with a range of staff from various stakeholders, there was generally steady agreement in CS4 with the propositions that BIM:

$>$ Improves efficiency ${ }^{\mathbf{d}}$ - associated with the category of Efficiency

$>$ Reduces rework ${ }^{\mathbf{d}}$ - also associated with Efficiency

$>$ Requires interoperability standards — associated with Alignment

$>$ Improves information management/flow/sharing — associated with Collaboration

> Capabilities must be understood by other stakeholders — associated with Assumptions/Constraints, Note ${ }^{\mathrm{d}}$ denotes some level of disagreement.

There was also steady disagreement with the proposition that BIM :

$>$ Does not improve documentation — associated with Assumptions/Constraints

Other propositions often mentioned included:

$>$ Improves buildability — associated with the category Design Functionality

> Improves co-ordination between some consultants — associated with Collaboration

$>$ Implementation and maintenance costs (including underlying IT) outweigh its usefulness - associated with Resources/Expenses. Note : $\underline{\text { disagreement here }}$

$>$ Requires specialised software - associated with Resources

$>$ Requires leadership within the company — associated with Assumptions/Constraints

\subsubsection{CASE STUDY CS5}

A project comprising a Police Station and Watch House, located in regional Australia. The project is being executed through the commercial project management arm of a Government department responsible for the built environment. The estimated project value is AU\$ 10 million.

Based on the interviews and discussions held with a range of staff from various stakeholders, there was generally steady agreement in Case Study CS5 with the propositions that BIM:

$>$ requires interoperability standards — associated with Alignment

$>$ Improves efficiency ${ }^{\mathbf{d}}$ - associated with the category of Efficiency

$>$ Improves information management/flow/sharing — associated with Collaboration

$>$ Requires appropriate training — associated with Initiatives

$>$ Requires a significant process re-structure (internal and external)) — associated with Initiatives

$>$ Must be clearly understood throughout the organization) — associated with Initiatives Note ${ }^{d}$ denotes some level of disagreement.

Other propositions often mentioned included:

$>$ Requires all project stakeholders to exchange and use the information — associated with Alignment

$>$ Requires a high economic investment — associated with Resources 
$>$ Is NOT more labour intensive in earlier stages of the project than 'traditional' systems — there is no consensus on this view.

\section{CROSS CASE STUDY COMPARISON}

The examination of these theoretical propositions in the cross-case-study analysis leads to the following overall conclusions regarding the business case for BIM:

Despite the wide variety of case-study characteristics previously described, analysis shows that the proposition that "BIM improves information management / flow / sharing" (Collaboration category) was one of the top four propositions most often mentioned across four of the five case studies, while equally strongly, the proposition that "BIM requires appropriate training" (Initiatives category) arose as a topic right across the whole range of five case studies.

Amongst CS1, CS2 and CS3 case studies, both the propositions that "BIM enhances confidence in the design outcomes", and that "BIM improves design" (both aspects of Design Functionality category) were mentioned often, whereas in the CS4 and CS5 case studies there was less mention of either of these propositions.

However, the proposition that "BIM requires interoperability standards" (Alignment category) was mentioned more often in CS5 study and somewhat in CS2, CS3and CS4, whilst in CS1 the issue of interoperability did not frequently appear. This may simply reflect the critical importance placed on this aspect of BIM by the initiators of the CS5 project, and by the involvement of more stakeholders actually exchanging data in the CS4 case study than in the other studies.

Similarly, the proposition that "BIM is more labour intensive in earlier stages of the project than 'traditional' systems” (Resources/Expenses category) was mentioned - and disagreed with - in responses from CS4, but appeared less often in the other case study responses, while the proposition that "BIM improves efficiency" (Efficiency category) was highly placed in discussions within CS2 and CS4, but less so in the other case studies.

Following is a summary of key business indicators (ValIT) found in the above-mentioned case studies - CS1 to CS5.

\subsection{INITIATIVES}

Analysis of a cross-case-study kind showed that a need for "significant organisational restructure", "clear understanding", "appropriate training", "software selection", "co-ordination role", and "process restructure" were all issues brought up in interviews, and agreed with in general (particularly training).

\subsection{ALIGNMENT ISSUES}

In this category, "BIM requires interoperability standards" was an issue with some agreement, whereas there appeared strong levels of agreement and disagreement with the proposition regarding BIM as an foundation for FM. BIM as a prerequisite for government projects did not appear to raise much interest - apart from the CS5 case study (which, it should be noted, already had government involvement).

\subsection{EFFICIENCY}

In particular, "BIM improves efficiency" was an issue often mentioned with agreement, whilst the "reduction of rework" proposition was also raised and agreed with. Whilst CS1, CS2 and CS3 showed mild evidence that BIM allows the small practitioner to participate in large projects, no comments were ventured from CS4 and CS5.

\subsection{DESIGN FUNCTIONALITY}

"Design", "buildability improvements", and "confidence in design" were issues mentioned in discussions and with agreement (but less so in case-study CS3, compared with disagreement on the same topic in CS5. 


\subsection{COLLABORATION}

"Improved information management" and "improved consultants co-ordination" were important issues mentioned in discussions and with agreement (but less so in case-study CS3 than in others).

\subsection{OTHER BENEFITS}

Little opinion was ventured on these propositions. However, some level of disagreement is evident as to whether BIM attracts innovative staff (CS1).

\subsection{RESOURCES / EXPENSES}

As could be expected, there appeared general agreement with "BIM requires specialised software", while discussion of "BIM requires high economic investment", and "costs outweigh usefulness" indicates that these were issues of disagreement often mentioned in interviews. However there was also some level of agreement with the "costly investment" proposition in two of the case-studies, indicating high cost may be a factor for some projects/stakeholders.

\subsection{RISKS}

"BIM and information ownership" was an issue often mentioned with agreement. However there was also some level of disagreement (CS4). In addition, there appeared differences of opinion between case-studies as to whether BIM is considered "sufficiently mature", and whether "BIM reduces risk in the project".

\subsection{ASSUMPTIONS/CONSTRAINTS/CONDITIONS}

Analysis indicates that it is generally not agreed that "BIM is a short-lived trend"; that "BIM does not improve documentation"; or that "BIM is only a software approach". The propositions that "BIM can be hindered by legal frameworks"; that its "capabilities must be understood by other stakeholders", and that it "requires leadership within the implementing company" were generally agreed upon right across the whole range of case-studies.

\subsection{EFFORT DISTRIBUTION}

A crucial aspect of BIM implementation relates to the perceived level of time-effort distribution curves described in the following Table 2. It was argued by a number of respondents that a clear understanding of this curve would have a direct implication on variations of fee structures. The table is a qualitative response to the perceived 'effort distribution' required to create BIM. Each diagram portrays a visual representation of apparent levels of effort as perceived by a number of respondents - no consensus was identified. The diagrams were elicited and discussed during each of the interviews. 
Table 2. Time-effort distribution curves: qualitative analysis.

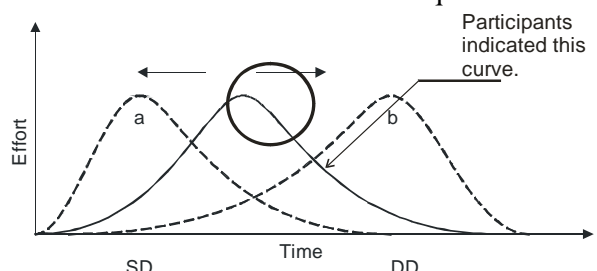

$\mathrm{SD}$
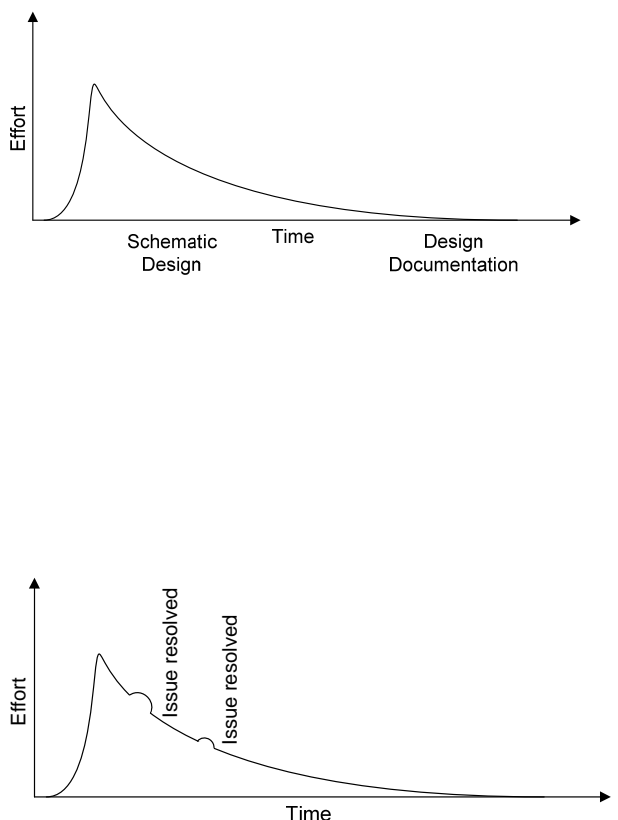

More commonly the effort distribution curve for traditional methods was identified as curve 'b'. Although some respondents believed that with traditional methods the effort was evenly distributed between the two phases but once BIM was implemented, the quicker the data could be put into the model the better (thus shifting the above curve to the left).

Once BIM is implemented, the distribution of effort is shifted to earlier stages of the project (curve a) - resulting in more of a straight line at the start of the project.

There were competing views amongst a number of CS2 respondents regarding the cash flow risk allocated by introducing BIM. For instance, the early input of effort could be seen as a cash-flow risk if hourly rates are being used; and over the whole life of the project BIM saved time, but not at the early stages. However, other stakeholders were of the opinion that with the same amount of effort more information was actually captured for use in the project.

Architects were of the view that substantial (but certainly not excessive) effort can be required quite early on in the project; but the effort quite rapidly declines until an issue needs clarification or resolution, and more detail is then needed. The issue results in a small increase of effort to resolve it, and the whole process is then repeated (with additional issues needing resolution and consequent effort) but always on a declining curve of effort versus time.

The method did not save the company time but risks have been reduced by eliminating 
The following heading aims to translate the above 'Cross Case Study Comparison' results into operational business model(s). The overall project was initially preparing to identify a single business model to adopt BIM however as the research project progressed it became evident that a single business model was not plausible. On the other hand the researchers found that there could be as many business models as there are projects and companies. This project focused on the business drivers and attributes behind BIM and established parallels with the well-established business model ValIT approach (ITGI 2006).

\section{CONCLUSION: DOES IT MAKE BUSINESS SENSE TO ADOPT BIM?}

Because of the widely varying array of alternatives regarding company size, industry sector (architectural, engineering and construction firms); experience with BIM, CAD and Information Technology in general; the differing sets of skills within the companies; the size, nature and strength of their relationships with other consultant firms; and whether the various stakeholders are private or public sector or a mixture, we have not attempted to come up with a generic business model to adopt BIM. Following, we outline the approach and hopefully provide a sufficient framework for individual companies to apply the Business Case process to their own (much more specific) situation.

In order for a business case to be reliable it must be developed to achieve specific objectives or outcomes taking into consideration the particular needs and characteristics of the company. The clearer the objectives are defined and the specific circumstances of the company analysed, the better the business case will be. Therefore, it is not possible to define a typical business case to adopt BIM. Furthermore, a single company could develop more than just one business case based on different scenarios. For instance, a scenario might assume that there will be no model sharing with third parties (Architects office only) whereas another might define a variation where collaboration between consultants is considered.

The following Business Case Framework aims to help companies that are interested in adopting BIM to gather the required information to undertake a business case.

Outcomes are the clear and measurable results sought. The outcomes are divided into: operational, technical and business capabilities. There can be more than one outcome on each of these capabilities.

Following are examples of outcomes expected when adopting BIM. These expected outcomes are based on results from the case studies.

\subsection{TECHNICAL CAPABILITY}

o Technical Outcome 1: Ability to produce the necessary drawings and documentation from the BIM model.

o Technical Outcome 2: Ability to exchange BIM models with consultants (structural, building services, and quantity surveyor).

\subsection{OPERATIONAL CAPABILITY}

o Operational Outcome 1: Ability to design in a 3D environment throughout the entire design process.

o Operational Outcome 2: Ability to use BIM to support design collaboration / information exchange with consultants.

o Operational Outcome 3: Ability to reduce error in documentation through better coordination between consultants. 


\subsection{BUSINESS CAPABILITY}

o Business Outcome 1: Ability to complete larger design projects with greater efficiency than present - this is particularly important for the smaller practice.

o Business Outcome 2: Improved design outcomes through better understanding of design alternatives by clients and designers. Measured by client satisfaction levels and designers qualitative opinions of design outcomes.

o Business Outcome 3: Reduced risks associated with information-related errors. Associated with information consistency in drawings, errors introduced during information exchanges, etc.

Fully implementing the above capabilities will certainly have an initial high cost but it is expected that organisations will recover rapidly and their performance will drastically improve. On a more individual level, the architects will now regain the ability to focus again on design and design opportunities as they should be spending less resources on design development - schedules and the massive amount of interior elevations. On the other hand BIM demands better coordination and knowledge of construction and construction processes.

It was identified that even if there are a number of small changes and steps BIM offers the client and design consultants the ability to accurately identify outcomes such as costs dynamically, thus making informed decisions on an array of information including figures, tables, drawings and renderings associated with the time dimension. Real time information is recorded without delay allowing more predictability for the design team and the owner.

Managing the change for architectural and engineering practices can be a challenge and furthering the technology is a full-time agenda that cannot be left only to chance. Practitioners should look for professionals to assist them in the transformation process, and governments should look for ways to assist the industry as we have seen in Singapore, Scandinavia and more recently in the US.

This is to set new documentation standards and protocols in industry, improve collaboration and move to better design technology - all with the aim of streamlining processes and improving efficiencies. This is not an option but basically reflects the current demands on an industry that has not shown clear improvement despite the demands of their clients and contractors. The benefits at operational, technical and business levels are too enormous to ignore or leave to chance. Practices are called on to take a proactive approach on the uptake of BIM technologies; in some cases even undertaking leadership and coaching roles. This is especially important for the Australian context as government intervention into industry's process and technical affairs is usually minimal - a bottom-up approach, and a very different scenario to that of Singapore, Scandinavia or the US. The authors of this paper are addressing ways to align parties in making a process transformation through industry seminars and publications.

\section{REFERENCES}

AIA, “The American Institute of Architects” website accessed in April 2008 www.aia.org

Amor, R. and Farag, I. (2001) Misconceptions about Integrated Project Databases, ITcon Journal, vol.6, pp.57-68.

Aranda-Mena, G., Chevez, A., Crawford, J. (2008). Final Report of "Business Drivers for BIM”, Project 2005-033-C, Cooperative Research Centre for Construction Innovation, Brisbane, Australia, January 2008.

AGC (2006), "The Contractors' Guide to BIM" Associated General Contractors (AGC) of America. Web site accessed in April 2008 www.agc.org

Bjork, B-C. and Penttila, H. (1989) A Scenario for the Development and Implementation of a Building Product Model Standard, Advances in Engineering Software, 11(4), pp. 176-186.

BuildingSMART, International Alliance for Interoperability website in April 2008 www.buildingsmartalliance.org

Construct-IT (2002). University of Salford, Salford Center for Research and Innovation "Developing a Vision of nD-Enabled Construction” UK 2002. 
Crawford, J., Aranda-Mena, G., Froese, T. and Chevez, A. (2008) "An Australian perspective of the business drivers for Building Information Modelling". submitted to the International Conference of Information Technology in Construction. ICCCBE-XII \& INCITE 2008, Beijing, China. 16-18 October 2008.

Fisher, N., Barlow, R., Garnett, N., Finch, E. and Newcombe, R. (1997) Project Modelling in Construction, Thomas Telford Ltd. London.

Froese, T., Aranda-Mena, G., Crawford, J. and Chevez, A. (2008) "Structuring the Business Case for Building Information Models" accepted for the Congrès annuel 2008 de la SCGC CSCE, Quebec, QC June 10-13 2008

Gann, D., Hansen, K.L., Bloomfield, D., Blundell, D., Cortty, R., Groak, S. And Jarret, N. (1996) Information Technology Decision Support in the Construction Industry: Current Developments and use in the US, Science Policy Research Unit, University of Sussex, Brighton, UK, September.

ITGI (2006) Enterprise Value: Governance of IT Investments, The Val IT Framework. IT Governance Institute: Rolling Meadows, Il, USA. <http://www.isaca.org/Val IT/>. ISBN 1-933284-32-3.

NIST (2004) "Cost Analysis of Inadequate Interoperability in the U.S. Capital Facilities Industry" National Institute of Standards and Technology.

Succar, B., Sher, W. and Aranda-Mena, G. (2007) “A proposed framework to investigate building information modelling through knowledge elicitation and visual models" Conference Proceedings of the Australasian Universities Building Education Association, Melbourne, Australia 4-5 July 2007.

Yin, R. (1994) Case study research: Design and methods (2nd ed.). Beverly Hills, CA: Sage Publishing. 